\title{
Photocatalytic performance of Fluorine-doped Anatase Titanium dioxide obtained through the Sol-Gel method
}

\author{
G.D. Gena ${ }^{1}$, T.H. Freeda ${ }^{2}$, K.Monikanda Prabu ${ }^{3 *}$ \\ ${ }^{1}$ Physics Research Centre, S.T. Hindu College, Affiliated to Manonmaniam Sundaranar University, Tirunelveli, Tamilnadu, India \\ ${ }^{2}$ Department of Physics, S.T. Hindu College, Affiliated to Manonmaniam Sundaranar University, Tirunelveli, Tamilnadu, India \\ 3* Physics Research Centre, S.T. Hindu College, Affiliated to Manonmaniam Sundaranar University, Tirunelveli, Tamilnadu, India
}

*Corresponding author: mkprabu1985@gmail.com, Tel: +919489474636

Available online at: www.isroset.org

Received: 28/Feb/2018, Revised: 12/Mar/2018, Accepted: 29/Mar/2018, Online: 30/Apr/ 2018

\begin{abstract}
Fluorine-doped anatase $\mathrm{TiO}_{2}$ nanoparticles are prepared using a simple sol-gel method in an $\mathrm{NH}_{4} \mathrm{~F}-\mathrm{H}_{2} \mathrm{O}-\mathrm{C}_{2} \mathrm{H}_{5} \mathrm{OH}$ mixed solution using the precursor TTIP. The prepared samples are characterized by X-ray diffraction, X-ray photoelectron spectroscopy, and photocatalytic properties. The anatase phase $\mathrm{TiO}_{2}$ nanoparticles are identified by X-ray diffraction data. The $\mathrm{X}$-ray photoelectron spectroscopy indicated that fluorine is doped effectively and most fluorine dopants might be present in the surface of $\mathrm{TiO}_{2}$ nanoparticles. The photocatalytic activity is evaluated by photocatalytic oxidation decomposition of methylene blue (MB) in atmospheric air under Visible light illumination. 84\% photocatalytic efficiency observed for $5 \mathrm{~W} \%$ fluorine-doped $\mathrm{TiO}_{2}$ nanoparticles. The higher photocatalytic activity predicted is due to the formation of photocatalytic reactive $\mathrm{OH}^{\prime}$ radicals.
\end{abstract}

Keywords - Fluorine-doped anatase $\mathrm{TiO}_{2}, \mathrm{XRD}$, XPS, Photocatalytic activity, Methylene Blue degradation

\section{INTRODUCTION}

Titanium dioxide $\left(\mathrm{TiO}_{2}\right)$ is one of the most popular highefficiency catalysts, due to the advantages of its high catalytic activity, environment-friendly properties, and low cost [1]. In order to improve its photocatalytic property, much care has been made in current years to modify $\mathrm{TiO}_{2}$ with different methods such as doping with metals or nonmetal ions and composite design with porous materials [2]. Plenty of methods applicable to the synthesis of $\mathrm{TiO}_{2}$, inclusive of chemical deposition, sol-gel process, microemulsion, and hydrothermal process. Of these, the solgel method is extensively used for photocatalytic applications due to their ability to control textural properties and surface oxides. The sol-gel process is based upon the development of a polymeric oxide network [3]. The familiar crystalline polymorphs of Titanium dioxide are anatase, rutile, and brookite. Each phase has differed with refractive index, chemical reactivity, photochemical response, and stability. Out of the three polymorphs, anatase phase is broadly applicable for photocatalysis [4]. The photocatalytic performance of anatase phase $\mathrm{TiO}_{2}$ nanoparticles enhanced by doped with non-metal ions. Fluorine ion is one of the nonmetal ions in order to improve the photocatalytic performance of $\mathrm{TiO}_{2}$ nanoparticles [5]. In the current study, we report the preparation and photocatalytic performance of anatase phase fluorine-doped $\mathrm{TiO}_{2}$ nanoparticles by sol-gel method.

\section{EXPERIMENTAL}

\section{Materials Used}

Titanium isopropoxide (TTIP, 97\%, Aldrich), Ammonium fluoride (Merck), Ethanol (Merck). Deionised Water.

Preparation of fluorine doped $\mathrm{TiO}_{2}$ nanoparticles A total of three fluorine-doped $\mathrm{TiO}_{2}$ nanoparticles is prepared via sol-gel method using the precursor TTIP, deionized water, and Ethanol. In this process, $100 \mathrm{ml}$ of ethanol is mixed with $15 \mathrm{ml}$ of TTIP in a beaker. $2 \mathrm{ml}$ of acetic acid is added to the above solution and stirred for 10 minutes using magnetic stirrer. Consequently, a suitable amount of aqueous ammonium fluoride solution is added dropwise to the above solution for hydrolysis reaction. Now the solution transformed to gel. After aging 24 hours the gel is filtered and dried. Powdered samples are used for further characterization.

\section{Material Characterization and Photocatalytic measurements \\ The prepared $\mathrm{TiO}_{2}$ nanoparticles are characterized by Powder XRD using XPERT-PRO diffractometer. XPS spectrum is recorded using MULTILAB 2000 X-Ray photoelectron spectroscopy instrument. \\ The photocatalytic activity of the fluorine-doped $\mathrm{TiO}_{2}$ nanoparticles is evaluated by the photodegradation of $\mathrm{MB}$ aqueous solution with an initial concentration of $12 \mathrm{ppm} / \mathrm{L}$. Two conventional lamps (18W) of fluorescent type is used}


as the light source. The degradation of the solution is analyzed by UV-Vis absorption spectra of MB recorded every 30 minutes. According to the standard curve between concentration and absorption, the value of $\left(\left(\mathrm{C}_{0}-\mathrm{C}_{1} / \mathrm{C}_{0}\right) \mathrm{x}\right.$ $100 \%$ ) was calculated, denoted as degradation efficiency.

\section{RESULTS AND DISCUSSION}

\section{XRD Analysis}

XRD patterns of fluorine-doped $\mathrm{TiO}_{2}$ nanoparticles are shown in Figure 1. The spikes of diffraction pattern have been present at the $2 \theta$ reflections about $25.36^{\circ}, 37.97^{\circ}$, $48.23^{\circ}, 54.08^{\circ}, 55.36^{\circ}, 63.03^{\circ}, 68.92^{\circ}, 70.53^{\circ}$ and $75.15^{\circ}$. Those peaks are assigned to (llll $\left.\begin{array}{lll}0 & 1\end{array}\right),\left(\begin{array}{lll}0 & 0 & 4\end{array}\right),\left(\begin{array}{lll}2 & 0 & 0\end{array}\right),\left(\begin{array}{lll}1 & 0 & 5\end{array}\right)$,

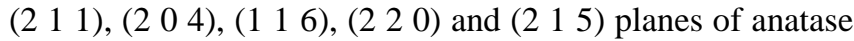
phase $\mathrm{TiO}_{2}$ and are indexed in accordance with the JCPDS file (JCPDS 21-1272) [6]. The ionic radius of fluorine ion $(0.133 \mathrm{~nm})$ is similar to that of oxygen ion $(0.132 \mathrm{~nm})$, as a consequence fluorine could be easily replaced oxygen atom and incorporated into the $\mathrm{TiO}_{2}$ crystal lattice without any change in crystal structure. Further, shifting of peaks in XRD inconsistent with JCPDS (25.28 ) at higher angles make sure the presence of fluorine in the $\mathrm{TiO}_{2}$ lattices [7]. Moreover, from the graph, it is noted that there are no additional peaks related to rutile or brookite phase. It suggests that fluorine doping leads to the formation of single-phase anatase $\mathrm{TiO}_{2}$. Such identical results are reported by $\mathrm{D}$. Li and his co-workers for fluorine-doped $\mathrm{TiO}_{2}$ nanoparticles obtained from spray pyrolysis method [8].

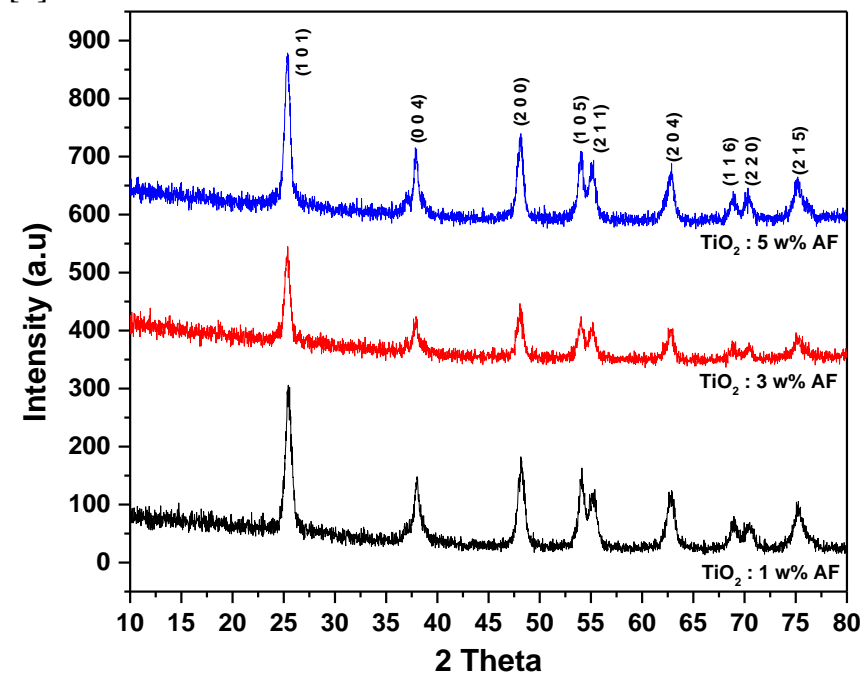

Fig. 1: XRD patterns of fluorine-doped $\mathrm{TiO}_{2}$ nanoparticles

Crystallite size of fluorine-doped $\mathrm{TiO}_{2}$ nanoparticles are usually estimated using the Scherrer formula,

$$
D=\frac{0.9 \lambda}{\beta \operatorname{Cos} \theta}
$$

Where $\mathrm{D}$ is the average crystallite size, $\lambda$ is the wavelength of the $\mathrm{X}$-ray radiation (1.54060 $\AA$ ), $\beta$ is the band broadening
(FWHM) of high intense (101) peak, and $\theta$ is the diffraction angle $[9,10]$. The average crystallite sizes are calculated to be $9.9 \mathrm{~nm}, 14.6 \mathrm{~nm}$, and $16.4 \mathrm{~nm}$ for 1,3 and $5 \mathrm{~W} \%$ fluorine- doped $\mathrm{TiO}_{2}$ nanoparticles, respectively.

\section{XPS Analysis}

The X-ray photoelectron spectroscopy (XPS) test was performed to determine the chemical composition of the samples for $5 \mathrm{~W} \%$ fluorine-doped $\mathrm{TiO}_{2}$ nanoparticles. XPS peaks indicated that the fluorine-doped $\mathrm{TiO}_{2}$ powder contains the elements $\mathrm{Ti}, \mathrm{O}$ and $\mathrm{F}$. The peak at 458.11 and $529.3 \mathrm{eV}$ corresponds to $\mathrm{Ti} 2 \mathrm{p}$ and $\mathrm{O} 1 \mathrm{~s}$, respectively [11]. Fluorine region of XPS spectrum gone into two regions (See Fig. 3).

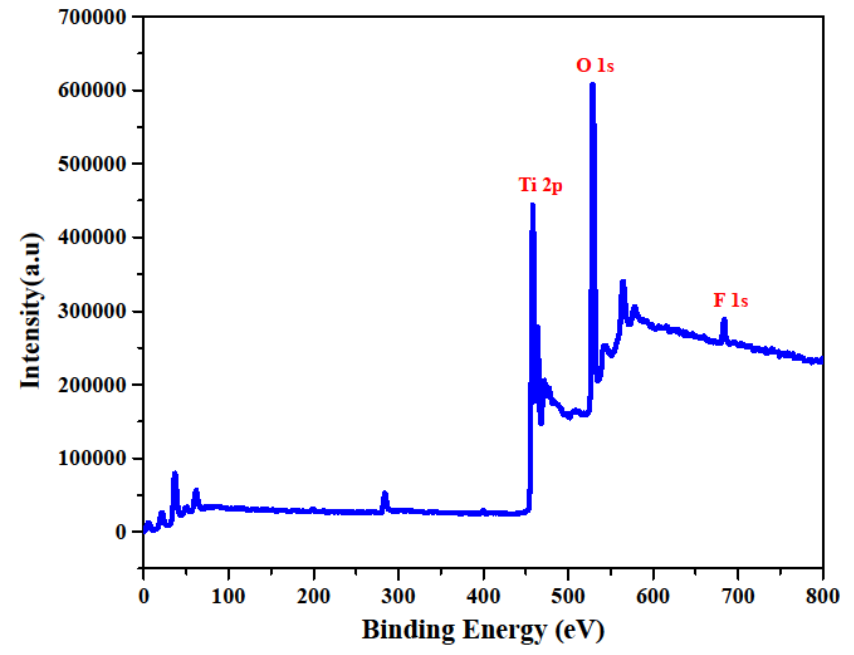

Fig. 2: X-ray photoelectron spectroscopy (XPS) of $5 \mathrm{~W} \%$ fluorine-doped $\mathrm{TiO}_{2}$ nanoparticles

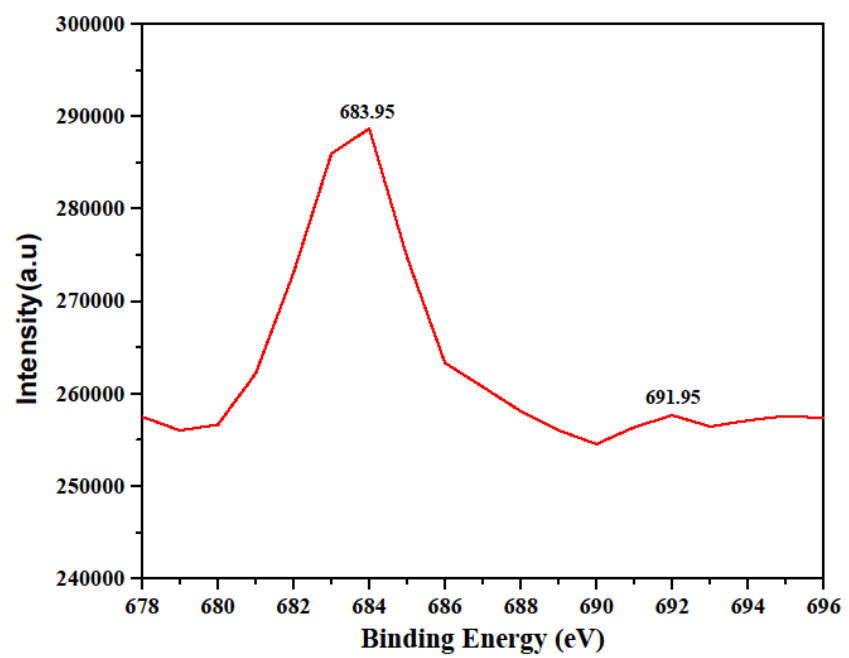

Fig. 3: XPS spectra for $\mathrm{F} 1 \mathrm{~s}$ regions of $5 \mathrm{~W} \%$ fluorine-doped $\mathrm{TiO}_{2}$ nanoparticles

The existing peak at $683.95 \mathrm{eV}$ was assigned to $\mathrm{F} 1 \mathrm{~s}$ and was occurred due to surface-adsorbed fluorine ions. The 
small peak at $691.95 \mathrm{eV}$ attributed to replacement of fluorine ions that occupied oxygen sites in the $\mathrm{TiO}_{2}$ crystal lattice [12-14]. Moreover, this results makes evident that the incorporation of fluorine ions into the crystal lattice or surface of $\mathrm{TiO}_{2}$ nanoparticles.

\section{Photocatalytic performance}

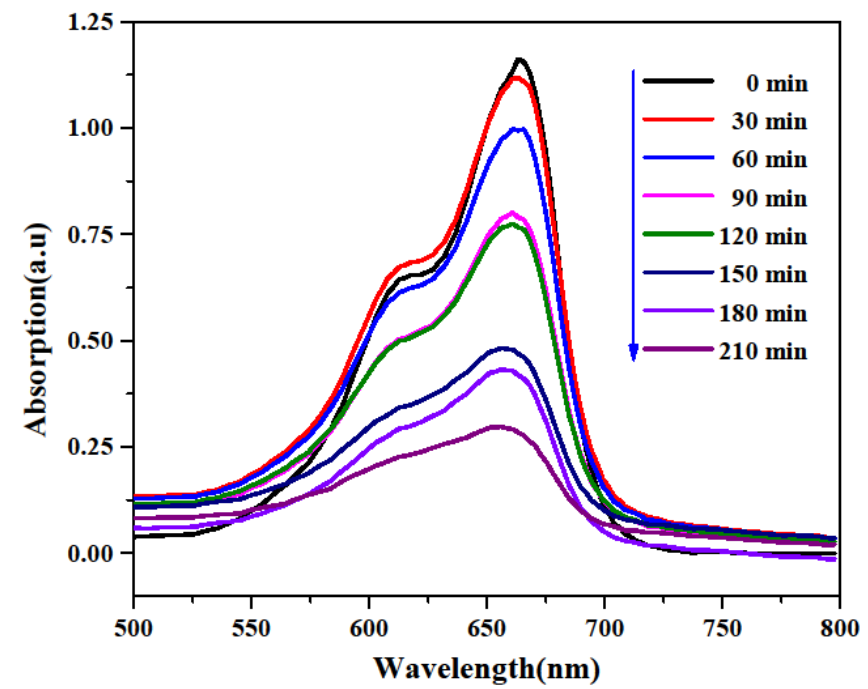

Fig. 4: Absorption spectra of MB in photodegradation assisted by $1 \mathrm{~W} \%$ fluorine-doped $\mathrm{TiO}_{2}$ nanoparticles

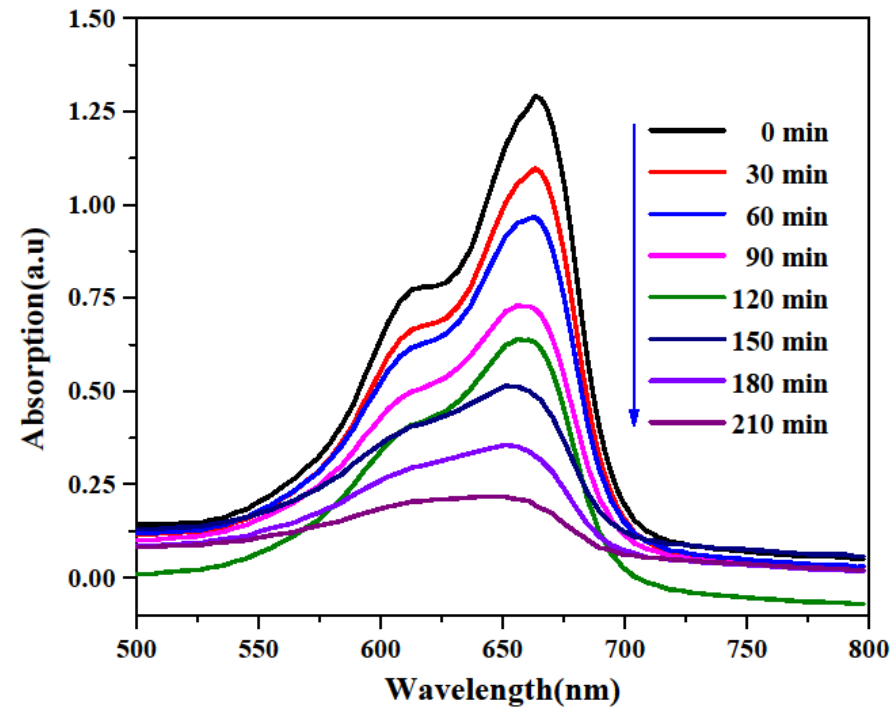

Fig. 5: Absorption spectra of MB in photodegradation assisted by $3 \mathrm{~W} \%$ fluorine-doped $\mathrm{TiO}_{2}$ nanoparticles

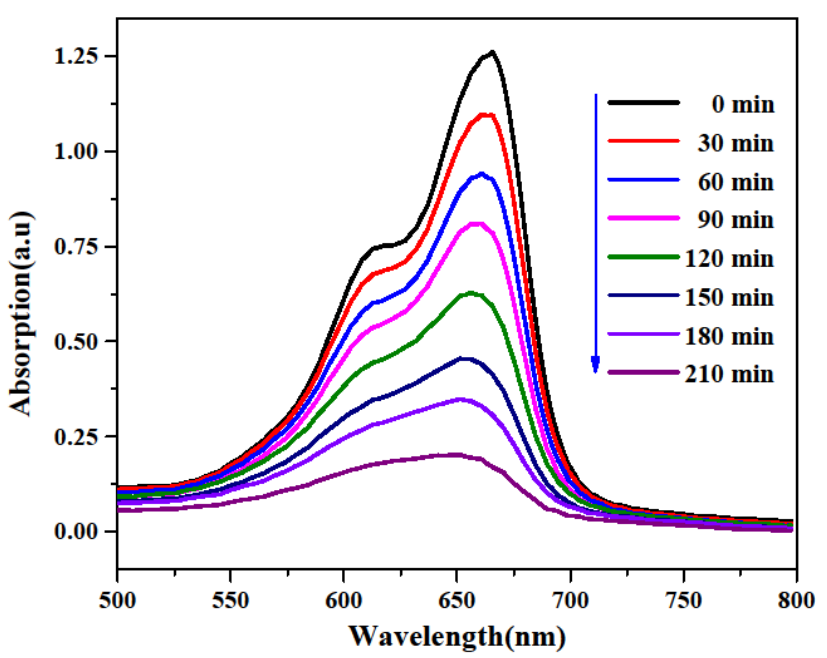

Fig. 6: Absorption spectra of MB in photodegradation assisted by $5 \mathrm{~W} \%$ fluorine-doped $\mathrm{TiO}_{2}$ nanoparticles

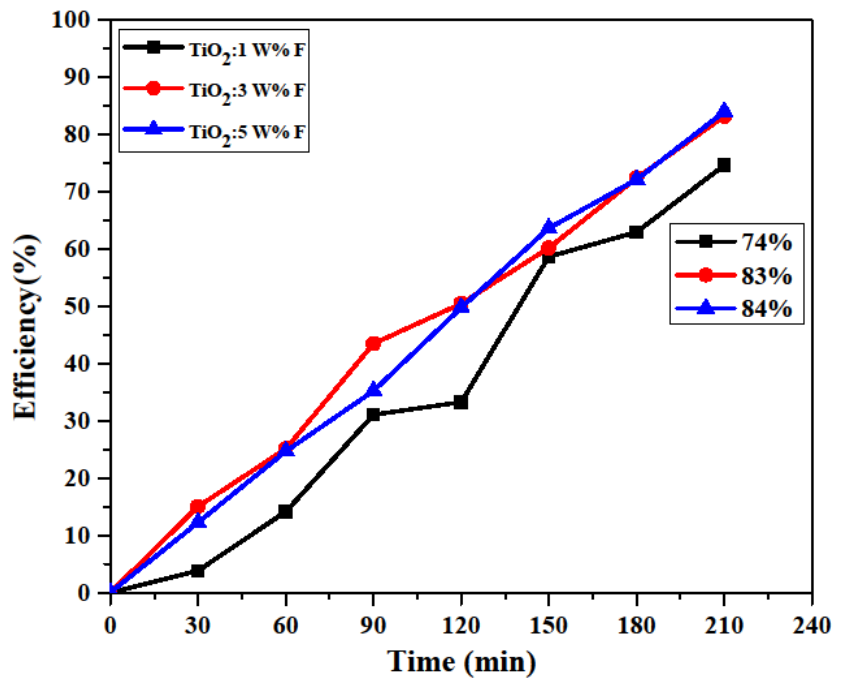

Fig. 7: Photocatalytic efficiency of fluorine-doped $\mathrm{TiO}_{2}$ nanoparticles

It is evident that the improved photocatalytic activity in the fluorine-doped $\mathrm{TiO}_{2}$ is mainly associated with the generation of oxygen vacancies. These vacancies behave as a site for the evolution of the active radicals [15]. Hence, a number of electrons are trapped in these trapping sites. As a result, photo-generated holes captured by $\mathrm{OH}$ groups enhanced to a greater extent which owing to the formation of more hydroxyl radicals $\left(\mathrm{OH}^{\circ}\right)$. Therefore, photo-catalytic degradation reaction increases for all percentage of fluorinedoped $\mathrm{TiO}_{2}$ nanoparticles [16]. Moreover, the stronger peak in the XPS results approaches that the surface adsorbed fluorine ions enhances the separation of photo-generated electron hole-pairs, resulting in the improved photocatalytic efficiency of fluorine-doped $\mathrm{TiO}_{2}$ nanoparticles, indirectly [17]. Highest degradation efficiency is observed for $5 \mathrm{~W} \%$ 
fluorine-doped $\mathrm{TiO}_{2}$ nanoparticles, which is due to the creation large number of electron-hole pairs under visible light by the doped fluorine ions on the surface of $\mathrm{TiO}_{2}$ nanoparticles.

\section{CONCLUSIONS}

In summary, the fluorine-doped $\mathrm{TiO}_{2}$ nanoparticles are prepared by the sol-gel method and investigated by XRD, XPS, and photocatalytic measurements. Anatase phase $\mathrm{TiO}_{2}$ nanoparticles are confirmed by XRD analysis. Successful doping of fluorine with $\mathrm{TiO}_{2}$ nanoparticles indicated by XPS spectrum. $5 \mathrm{~W} \%$ fluorine-doped $\quad \mathrm{TiO}_{2}$ nanoparticles demonstrated a higher degradation efficiency under visible light irradiation than that of $1 \mathrm{~W} \%$ fluorine-doped $\mathrm{TiO}_{2}$ nanoparticles. This result indicates that our prepared fluorine- doped $\mathrm{TiO}_{2}$ nanoparticles is a very interesting and promising photocatalytic material and has good potential for application to water purification.

\section{REFERENCE}

[1]. Z. Wu, Q. Wu, L. Du, C. Jiang, L. Piao, "Progress in the synthesis and applications of hierarchical flower-like $\mathrm{TiO}_{2}$ nanostructures", Particuology, Vol.15, pp.61-70, 2013.

[2]. B. Wu, R. Yuan, X. Fu, "Structural characterization and photocatalytic activity of hollow binary $\mathrm{ZrO}_{2} / \mathrm{TiO}_{2}$ oxide fibers", Journal of Solid State Chemistry, Vol.182, Issue.3, pp.560-565, 2009.

[3]. E.I. Seck, J.M.D. Rodriguez, E. P. Melian, C. F. Rodriguez, O.M.G. Diaz, D. P. Carrizo, J. P. Pena, "Comparative study of nanocrystalline titanium dioxide obtained through sol-gel and sol-gel-hydrothermal synthesis", Journal of Colloid and Interface Science, Vol.400, pp.31-40, 2013.

[4]. R. S. Sonawane, S. Ramakrishna, "Facile method for the selective growth of rice like rutile $\mathrm{TiO}_{2}$ from peroxotitanate gel and its photo-activity", Materials Science and Engineering B, Vol.177, pp.652-660, 2012.

[5]. M.V. Dozzi, C. D’Andrea, B. Ohtani, G. Valentini, E. Selli, "Fluorine-Doped $\mathrm{TiO}_{2}$ Materials: Photocatalytic Activity vs Time-Resolved Photoluminescence", Journal of Physical Chemistry C, Vol.117, Issue.48, pp.25586-25595, 2013.

[6]. J. Ding, J. Lin, J. Xiao, Y. Zhang, Q. Zhong, S. Zhang, L. Guo, M. Fan, "Effect of fluoride doping for catalytic ozonation of lowtemperature denitrification over cerium-titanium catalysts", Journal of Alloys and Compounds, Vol.665, pp.411-417, 2016.

[7]. V. Balek, D. Li, J. Subrt, E. Vecernıkova, S. Hishita, T. Mitsuhashi, H. Haneda, "Characterization of nitrogen and fluorine co-doped titania photocatalyst: Effect of temperature on microstructure and surface activity properties", Journal of Physics and Chemistry of Solids, Vol.68, pp.770-774, 2007.

[8]. D. Li, H. Haneda, S. Hishita, N. Ohashi, N. K. Labhsetwar, "Fluorine-doped $\mathrm{TiO}_{2}$ powders prepared by spray pyrolysis and their improved photocatalytic activity for decomposition of gasphase acetaldehyde", Journal of Fluorine Chemistry, Vol.126, Issue.1, pp.69-77, 2005.

[9]. J. A. Khan, C. Han, N. S. Shah, H. M. Khan, M. N. Nadagouda, V. Likodimos, P. Falaras, K. O'Shea, D. D. Dionysiou, "Ultraviolet-Visible Light-Sensitive High Surface Area Phosphorous-Fluorine-Co-Doped $\mathrm{TiO}_{2}$ Nanoparticles for the Degradation of Atrazine in Water", Environmental Engineering Science, Vol.31, Issue.7, pp. 435-446, 2014.
[10]. Y. Zhang, J. Wan, Y. Ke, “A novel approach of preparing $\mathrm{TiO}_{2}$ films at low temperature and its application in photocatalytic degradation of methyl orange", Journal of Hazardous Materials, Vol.177, Issues.1-3, pp.750-754, 2010.

[11]. J. C. Yu, J. Yu, W. Ho, Z. Jiang, L. Zhang, "Effects of F-Doping on the Photocatalytic Activity and Microstructures of Nanocrystalline $\mathrm{TiO}_{2}$ Powders", Chem. Mater., Vol.14, Issue.9, pp.3808-3816, 2002.

[12]. N. Todorova, T. Giannakopoulou, G. Romanos, T. Vaimakis, J. $\mathrm{Yu}$, C. Trapalis, "Preparation of Fluorine-Doped $\mathrm{TiO}_{2}$ Photocatalysts with Controlled Crystalline Structure", International Journal of Photoenergy, 534038, pp. 1-9, 2008.

[13]. D. Huang, S. Liao, S. Quan, L. Liu, Z. He, J. Wan, W. Zhou, "Preparation of anatase $\mathrm{F}$ doped $\mathrm{TiO}_{2}$ sol and its performance for photodegradation of formaldehyde", J Mater Sci, Vol.42, Issue.19, pp.8193-8202, 2007.

[14]. J. Yu, Z. Liu, H. Zhang, T. Huang, J. Han, Y. Zhang, D. Chong, "Synergistic effect of $N$ - and F-codoping on the structure and photocatalytic performance of $\mathrm{TiO}_{2}$ ", Journal of Environmental Sciences, Vol.28, pp.148-156, 2014.

[15]. D. Li, H. Haneda, S. Hishita, N. Ohashi, "Visible-Light-Driven NF-Co doped $\mathrm{TiO}_{2}$ Photocatalysts. 2. Optical Characterization, Photocatalysis, and Potential Application to Air Purification”, Chem. Mater, Vol.17, Issue.10, pp. 2596-2602, 2005.

[16]. H. Zhang, G. Miao, X. Ma, B. Wang, H. Zheng, "Enhancing the photocatalytic activity of nanocrystalline $\mathrm{TiO}_{2}$ by codoping with fluorine and yttrium", Materials Research Bulletin, Vol.55, pp.26-32, 2014.

[17]. J. Yu, W. Wang, B. Cheng, B. L. Su, "Enhancement of Photocatalytic Activity of Mesoporous $\mathrm{TiO}_{2}$ Powders by Hydrothermal Surface Fluorination Treatment", J. Phys. Chem. C, Vol.113, Issue.16, pp.6743-6750, 2009. 